\title{
Depicting Medullary Thyroid Cancer Recurrence:The Past and the Future of Nuclear Medicine Imaging
}

\author{
Evangelia Skoura ${ }^{1, *}$ \\ ${ }^{1}$ Nuclear Medicine Department, Evangelismos Hospital, Athens, Greece \\ ${ }^{*}$ Corresponding author: Evangelia Skoura, Nuclear Medicine Department, Evangelismos Hospital, Ipsilandou Street, Athens 10676, Greece. Tel: +30-6946143924, Fax:+30-2107259305, \\ E-mail: Iskoura@yahoo.gr.
}

Received: September 13, 2012; Revised: January 25, 2013; Accepted: February 01, 2013

\begin{abstract}
Context: Inherited and sporadic medullary thyroid cancer (MTC) is an uncommon and medically challenging malignancy. Even if the extent of initial surgery is deemed adequate, the recurrence rate remains high, up to $50 \%$ in most series. Measurement of serum calcitonin is important in the follow-up of patients with MTC, and reliably reflects the existence of the disease.

Evidence Acquisition: There is no single sensitive diagnostic imaging method to reveal all MTC recurrences or metastases. Conventional morphologic imaging methods (U/S, CT, and MRI) and several methods of nuclear medicine have been used for this purpose with variable accuracy.

Results: The main role of nuclear medicine imaging is the detection of residual or recurrent tumor in the postoperative follow-up. In this review we present the radiopharmaceuticals used in the diagnosis of MTC recurrence, and comparison among them.

Conclusions: The most used radiopharmaceuticals labelled with $\gamma$ emitters are: Metaiodobenzylguanidine (MIBG), labelled with ${ }^{131}$ or 123I, ${ }^{111}$ In-pentetreotide (Octreoscan), 99m Tc-pentavalent dimercaptosuccinic acid (99m Tc(V)-DMSA), and 99m Tc-EDDA/HYNIC-Tyr3Octreotide ( Tektrotyd). The radiopharmaceuticals labelled with a positron-emitting radionuclide ( $\beta+)$, suitable for positron emission tomography (PET) imaging are: 18F-fluorodeoxyglucose (18F-FDG), 18F-fluorodihydroxyphenylalanine (18 $\mathrm{F}-\mathrm{DOPA})$, and 68Ga-labelled somatostatin analogues (68 Ga-DOTATATE or DOTATOC).
\end{abstract}

Keywords: Medullary Thyroid Cancer-MTC; Calcitonin; Pentetreotide; 3-Iodobenzylguanidine; Positron-Emission Tomography; Fluorodeoxyglucose F18

\section{Introduction}

Inherited and sporadic medullary thyroid cancer (MTC) is an uncommon and medically challenging malignancy which originates from the parafollicular calcitonin-secreting cells of the thyroid. MTC makes up 3\%-10\% of all thyroid cancers and $13.4 \%$ of all thyroid-related deaths (1, 2 ). Its low incidence is the limitation of both widespread clinical expertise and definitive randomized clinical trials (1). MTC may occur in sporadic (75\% of cases) or hereditary (25\% of cases) forms which include multiple endocrine neoplasia (MEN) types IIA and IIB, and isolated familial MTC (2).

When no distant metastasis is present, the curative treatment for MTC is total thyroidectomy and lymph node dissection $(1,3)$. Nevertheless, the recurrence rate remains high, up to $50 \%$ in most series (1). Measurement of the serum calcitonin is important in the follow-up of patients with MTC, and reliably reflects the presence and volume of disease in most of them. Calcitonin levels should be measured 2-3 months postoperatively, as it has a half-life of about $30 \mathrm{~h}$ (3). When calcitonin is undetectable, a pentagastrin stimulation test may be performed to exclude any residual disease (1). If both the basal and the stimulated serum calcitonin are undetectable the patient is in complete biochemical remission and has about a $3 \%$ chance of biochemical recurrent disease during follow-up (4). It is reported that biochemical cure predicted a survival rate of $97.7 \%$ at 10 years (5).

When MTC recurrence occurs, reoperation seems to be the only treatment strategy that, with good patient selection, can result in local disease control. Neither, conventional chemotherapy, nor external beam radiotherapy has a significant role in the treatment of these patients. Recent on-going trials with new classes of drugs, as tyrosine kinase inhibitors (e.g. Vandetanib and Cabozanitinib), have shown promising results (1). However, the most important prognostic factor in patients with recurrent MTC remains the early diagnosis, careful patient se-

Implication for health policy/practice/research/medical education:

In this review we present the radiopharmaceuticals used in the diagnosis of MTC recurrence. For such purpose, a great number of radiopharmaceuticals, either for $\gamma$-camera or positron emission tomography (PET), have been proposed taking advantage of the specific expression of receptors, hormone transporters or molecular targets by MTC lesions.

Copyright (C) 2013, Research Institute For Endocrine Sciences and Iran Endocrine Society; Published by Kowsar. This is an Open Access article distributed under the terms of the Creative Commons Attribution License (http://creativecommons.org/licenses/by/3.0), which permits unrestricted use, distribution, and reproduction in any medium, provided the original work is properly cited. 
lection, and recognition of the recurrent lesions (3).

Nowadays, there is no single sensitive diagnostic imaging method to reveal all MTC recurrences or metastases. Conventional morphologic imaging methods, neck ultrasound (U/S), cervical, thoracic, and abdominal computed tomography (CT), and thoracic and abdominal magnetic resonance imaging have been used for this purpose with variable accuracy (6). However, often MTC lesions are difficult to localize due to their small size and the reliable differentiation between scar tissue and recurrent tumor is frequently not possible $(1,6,7)$. Ultrasonography $(U / S)$ has shown a lymph node detection rate of $28 \%-78 \%$, compared to $38 \%-70 \%$ and $44 \%-74 \%$ for CT and MRI, respectively (7). Generally, the combined use of various diagnostic procedures allows the identification of recurrent tumor in approximately $40 \%$ of patients (6).
Several methods of nuclear medicine have been used for the detection of MTC recurrent lesions, especially when there are elevated levels of serum calcitonin and the conventional imaging has negative results for such purpose, a great number of radiopharmaceuticals, either for $\gamma$-camera or positron emission tomography (PET), have been proposed (8). The most difficult challenge was to find a technique with high sensitivity and specificity in detecting tumor remnant or relapse after surgery.

In this review we present the radiopharmaceuticals used in diagnosis of MTC recurrence (Table 1), although some of them, as radiolabelled monoclonal antibodies, can be considered either of historical or experimental value and the use of ${ }^{99 \mathrm{~m}} \mathrm{Tc}(\mathrm{V})$-DMSA is going to be abandoned $(8,9)$.

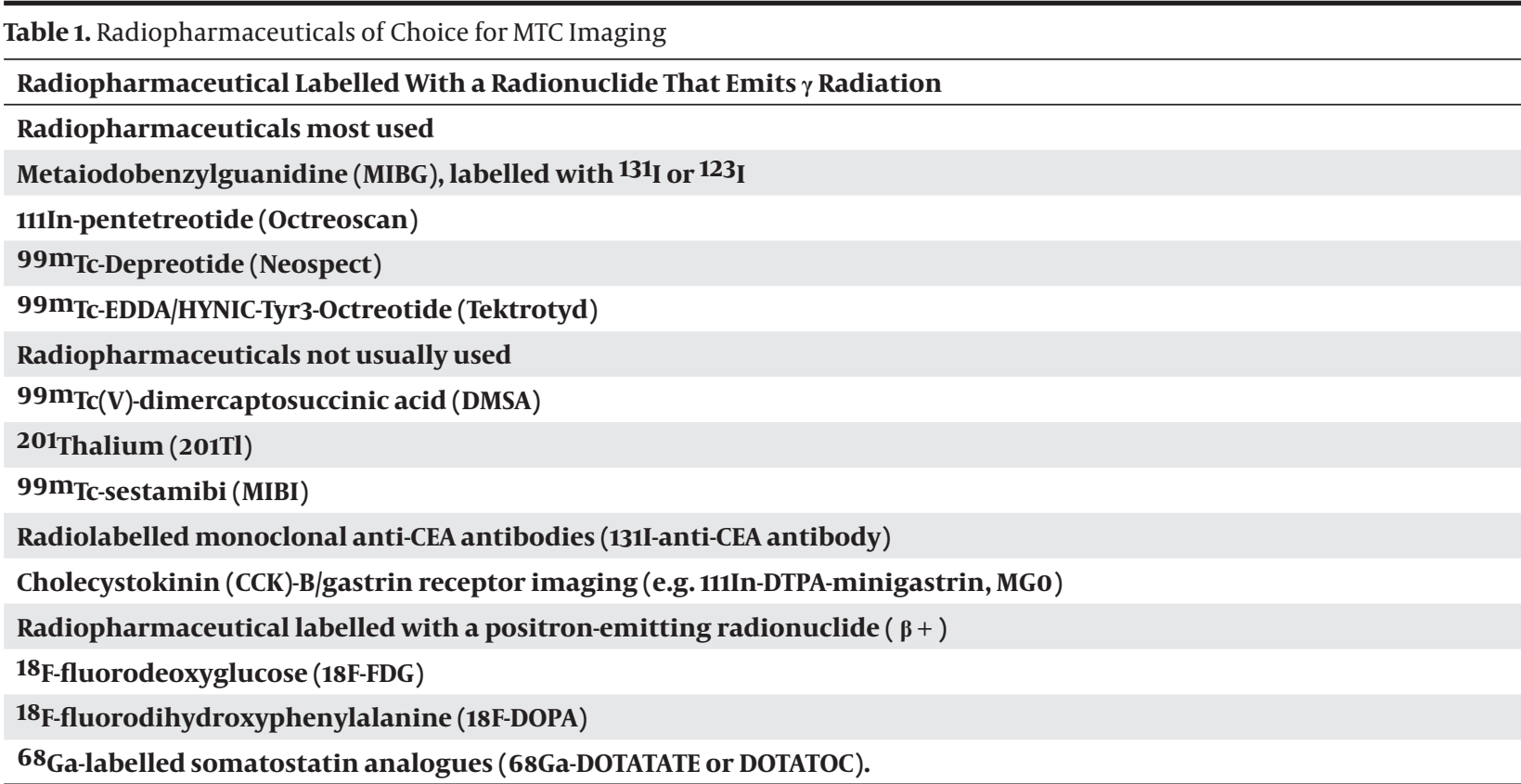

\section{Radiopharmaceuticals}

\subsection{Single Photon Emission Tracers}

\subsubsection{Technetium-99m Pentavalent Dimercaptosuccinic Acid, $99 m \mathrm{Tc}(V)-D M S A$}

The main clinical role of ${ }^{99 \mathrm{~m}} \mathrm{Tc}(\mathrm{V})$-DMSA was in patients with primary or recurrent MTC (10). According to published studies, its sensitivity ranged from $50 \%$ to $80 \%$ (11). The wide range of sensitivity could be explained by the use of different commercial kits, as a result of instability of the isomeric composition of their manufactured product (10).

The ${ }^{99 \mathrm{~m}} \mathrm{Tc}(\mathrm{V})$-DMSA imaging is valuable prior and after the surgical removal of MTC (12). In the preoperative setting the uptake of ${ }^{99 \mathrm{~m}} \mathrm{Tc}(\mathrm{V})$-DMSA by the tumor is as- sessed. Postoperatively, it is used to evaluate the presence of residual disease. During follow-up period, ${ }^{99 \mathrm{~m}} \mathrm{Tc}(\mathrm{V})$ DMSA could localize the site of recurrence when calcitonin level starts to increase (10).

The intensity of ${ }^{99 m} \mathrm{Tc}(\mathrm{V})$-DMSA uptake in MTC lesions varies from minimal to high depending on the involved tissue, e.g. uptake in soft tissue sites appears more intense than in bone metastases (10).

Nowadays the use of ${ }^{99 \mathrm{~m}} \mathrm{Tc}(\mathrm{V})$-DMSA is going to be abandoned and in most countries it is not commercially available (9).

\subsubsection{Radioiodinated Metaiodobenzylguanidine (MIBG)}

Radioiodinated metaiodobenzylguanidine (MIBG), first used in 1980 for the imaging of the tumors of the adrenal medulla, is a radiopharmaceutical specific for tumors originating from the neural crest, including MTC 
(6). MIBG, resulting from the combination of the benzyl group of bretylium and the guanidine group of guanethidine, is a noradrenaline (norepinephrine) analogue. It is actively transported into noradrenaline granules of sympathetic nerve terminals by the noradrenaline transporter (type 1 uptake mechanism) (13). It exploits the type 1 uptake mechanism at the cell membrane, and is stored within intracellular storage vesicles MIBG can be labeled with either 131 I- or 123 I. Nowadays, both radiopharmaceuticals (131 I- and 123I -MIBG) are available for diagnostic purposes but the use of 123I -MIBG is to be considered the agent of choice, as it has a more favorable dosimetry (159 $\mathrm{KeV}$ photon energy, T1/2=13.2h, fewer particulate emissions) and provides better image quality, better photon detection and greater sensitivity in tumor detection (8). Also, when 123I-MIBG is used, the higher photon flow allows high-quality single-photon emission computed tomography (SPECT) to be performed (13).

In 1984, the first positive case of ${ }^{131}$ I-MIBG uptake in a patient with MEN IIA was reported, where there was uptake in both the primary MTC and the coexistent pheochromocytoma (10). After this, the results of many series of MTC patients studied with MIBG have been published $(11,14)$. Although the results of the first studies were encouraging, the following results were controversial (15). A study showed a high rate of specificity, reaching $95 \%$ but sensitivity was much lower, only $30 \%$, while other researchers have reported better detection results in familial rather than in sporadic MTC, and higher sensitivity in detection of residual or recurrent lesions in comparison with distant metastases (15). This wide range of sensitivity values might be related to the histological heterogeneity of MTC and the possible anaplastic transformation of the metastases. In the last years, new radiopharmaceuticals have been proposed for the imaging of MTC, and the use of MIBG is very limited.

\subsubsection{Somatostatin Receptor Scintigraphy (SRS)}

Somatostatin is a regulatory peptide widely distributed in the human body. In the nervous system, somatostatin acts as a neurotransmitter, whereas its hormonal activities include the inhibition of the physiologic and tumorous release of growth hormone, insulin, glucagon, gastrin, serotonin, and calcitonin (16). Its other actions are an antiproliferative effect on tumors and also specific regulation of immune responses (16). Somatostatin action is mediated through membrane-bound receptors, of which five have been cloned (sst1-sst5), and they all belong to the family of G-protein-coupled receptors (17). Somatostatin is a peptide with two forms, containing 14 and 28 amino acids, respectively (17). Both bind to all subclasses of somatostatin receptors but are rapidly degraded in the blood by peptidases and have a short half life $\left({ }_{\mathrm{r}} 1 / 2=1-2 \mathrm{~min}\right)(17)$. Various synthetic somatostatin analogues have been made to increase resistance to peptidases and thereby allow systemic delivery by virtue of longer circulation times. These synthetic somatostatin analogues have varying affinity for the different types of somatostatin receptors (8). However, only sst2, sst5 and, to some extent, sst3 have a high affinity for the commercially available synthetic peptides, octreotide, lanreotide, and vapreotide (16). The most widely used is an 8-amino acid peptide, octreotide, with a half-life of T1/2=2.83 days (17). This peptide has been radiolabelled as [111 In] diethylenetriaminepentaacetic acid (DTPA)-octreotide (Octreoscan, Covidien, Petten, The Netherlands), and it has highest affinity for sstr2 and is suitable for imaging on a gamma camera (17).

Extremely variable results of Octreoscan in patients with MTC have been reported in the literature (6). The tumor detection rate ranges between $20 \%$ and $64 \%$ (8). According to a study, the sensitivity of Octreoscan is lower than this of conventional imaging (37\%), but others support that the sensitivity is 50\%-75\% and higher than radiolabelled MIBG and similar or slightly superior to that ${ }^{99 \mathrm{~m} T c}$ (V)-DMSA (18-20). SPECT imaging may increase the lesion detection in the neck and liver. The results of in vitro studies have shown that the incidence of somatostatin receptors is higher in differentiated MTC lesions, as their density is directly related to tumor differentiation (21). These results have been confirmed by clinical studies showing that the sensitivity of Octreoscan is higher for detection of involved lymph nodes in patients with occult MTC, typically associated with less aggressive behaviour. On the opposite, this method is less sensitive in cases with distant metastases and progressive disease (22).

Several attempts have been performed to label somatostatin analogues with ${ }^{99 \mathrm{~m}} \mathrm{Tc}$, which is the most available radionuclide. So, ${ }^{99 \mathrm{~m}}$ Tc-EDDA/HYNIC-Tyr ${ }^{3}$-Octreotide (Tektrotyd) scintigraphy seems to have significant sensitivity and specificity in MTC (23). It seems to be clinically useful in the follow-up of patients with MTC, with an overall sensitivity of $79.5 \%$, and a specificity of $83.3 \%$ (24).

Indication for radiolabelled somatostatin, besides the follow-up of patients with known disease, is also the selection of patients with inoperable tumors for peptide receptor radionuclide therapy with ${ }^{90} \mathrm{Y}^{0} \mathrm{DOTA}^{0}$-Tyr ${ }^{3}$-octreotide $\left({ }^{90}{ }^{Y}\right.$-DOTATOC) or ${ }^{177} \mathrm{Lu}-\mathrm{DOTA}{ }^{0}-\mathrm{Tyr}^{3}$-octreotate $\left({ }^{177}\right.$ Lu-DOTA-TATE) (23).

\subsection{4. ${ }^{201}$ Thalium (201Tl)}

${ }^{201} \mathrm{Tl}$ has been recognized as a tumor-imaging agent since 1976 (10). Accumulation of 201Tl in both primary and recurrent MTC lesions has been reported with sensitivity and specificity reaching up to $91 \%$ and $100 \%$, respectively $(25,26)$. The main problem of the imaging with 201Tl is the nonspecific uptake in the liver and lungs which reduces its sensitivity in detecting metastases in these organs (10).

\subsection{5. ${ }^{99 \mathrm{~m}}$ Tc-sestamibi (MIBI)}

The role of ${ }^{99 m}$ Tc-MIBI has been investigated as an imag- 
ing agent in patients with recurrent MTC. A study showed that ${ }^{99 \mathrm{~m}}$ Tc-MIBI was more sensitive than CT for the detection of MTC recurrence in the neck and chest, but CT was more sensitive for lesions in the liver (27). Also, ${ }^{99 \mathrm{~m} T c-}$ diphosphonate bone scintigraphy had better sensitivity in the detection of bone metastases than ${ }^{99 m}$ Tc-MIBI (27). Another study has demonstrated that the sensitivities of ${ }^{99 \mathrm{~m}} \mathrm{Tc}-\mathrm{MIBI},{ }^{201} \mathrm{Tl}$ and ${ }^{99 \mathrm{~m}} \mathrm{Tc}(\mathrm{V})$-DMSA were $47 \%, 19 \%$ and 95\%, respectively (28).

\subsubsection{Radiolabelled Monoclonal Antibodies}

Several monoclonal antibodies have been used to image patients with MTC. These include ${ }^{123} \mathrm{I}-,{ }^{131} \mathrm{I}$ - and ${ }^{111} \mathrm{In}$-CEA (carcinoembryonic antigen) antibodies, both whole antibody and fragments, and ${ }^{111}$ In-anticalcitonin antibody (10). Results from imaging with monoclonal antibodies have been varied, ranging from $0 \%$ with anticalcitonin antibody to $78 \%$ with ${ }^{131}$ I-anti-CEA antibody (29). The results with labeled anti-CEA antibodies seem to be related to the aggressiveness of the neoplasm (29).

A study compared imaging with ${ }^{131}$ I-anti-CEA antibody and ${ }^{131}$ I-MIBG and showed significantly higher lesion detection with the antibody (30). Another study compared the results of imaging with ${ }^{131} \mathrm{I}-\mathrm{MIBG},{ }^{201} \mathrm{Tl}$ and ${ }^{111} \mathrm{In}$ anti-CEA antibody and showed that imaging with the antibody yielded the best results, while another study showed that the sensitivity of imaging with ${ }^{99 \mathrm{~m}} \mathrm{Tc}(\mathrm{V})-\mathrm{DM}$ SA and ${ }^{131}$ I-anti-CEA antibody was far superior to imaging with MIBG (14).

\subsubsection{Cholecystokinin (CCK)-B/Gastrin Receptor Imag- ing}

Cholecystokinin (CCK) is a peptide hormone, originally discovered in the gastrointestinal tract in 1928 (31). Three types of CCK receptors have been identified so far: CCK1, CCK2, and CCK2i4sv receptors (31). A surprising high incidence of CCK2 receptors, reaching $90 \%$, has been identified in MTC; whereas, differentiated thyroid cancers do not express CCK2 receptors (32).

The first published clinical study with ${ }^{111}$ In-DTPA-minigastrin (MG0) was reported in 1999 (33). Since then several studies in patients with MTC have been performed with both gastrin-like and CCK-like peptides (111 In-DTPA-MG0, ${ }^{111}$ In-DOTA-MG11, ${ }^{111}$ In-DOTA-CCK8, ${ }^{99 \mathrm{~m}}$ Tc-Demogastrin2) in the past few years $(34,35)$. The reported detection rate of ${ }^{111}$ In-DTPA-MGO imaging in patients with MTC is up to $87 \%$ (35). Future studies are warranted to establish the optimal CCK2 receptor targeting peptide.

\subsection{Positron-Emitting Radiopharmaceuticals for PET Imaging}

Positron Emission Tomography (PET) complements anatomic imaging by adding unique metabolic information to the characterization of malignancy. The method of ${ }_{\mathrm{P}} \mathrm{ET} / \mathrm{CT}$ has the great advantage of combining func- tional and anatomic imaging at the same time, following image fusion.

It uses the ability of radiolabelled tracers to be takenup by certain tumours, and thus selectively assesses the function of different metabolic pathways of the specific tissue. Positron-emitting isotopes frequently used for PET imaging include oxygen-15 $\left({ }^{15} \mathrm{O}\right)$, nitrogen-13 $\left({ }^{13} \mathrm{~N}\right)$, carbon- $11\left({ }^{11} \mathrm{C}\right)$, and fluorine- $18\left({ }^{18} \mathrm{~F}\right)$.

The positron-emitting radiopharmaceuticals currently available for neuroendocrine tumors imaging may be divided into two groups: tracers which mark cell metabolism - $\left[{ }^{18} \mathrm{~F}\right]$ FDG (fluorodeoxyglucose), $\left[{ }^{18} \mathrm{~F}\right] \mathrm{DOPA}$ (fluoro-dihydroxy-fluorophenylalanine), $\left[{ }^{11} \mathrm{C}\right] \mathrm{HTP}\left(\left[{ }^{11} \mathrm{C}\right] 5\right.$-hydroxytryptophan), and tracers being specific ligands for receptors expressed on these cells- $\left[{ }^{68} \mathrm{Ga}\right]$ DOTA-peptides like $\left[{ }^{68} \mathrm{Ga}\right]$ DOTA-TOC and $\left[{ }^{68} \mathrm{Ga}\right]$ DOTA-TATE (36).

\subsection{1. ${ }^{18} \mathrm{~F}-\mathrm{FDG}$}

${ }^{18} \mathrm{~F}$-fluorodeoxyglucose $\left({ }^{18} \mathrm{~F}-\mathrm{FDG}\right)$ was the first tracer used, reflecting the increased glucose uptake in malignant tumours (36). During the past few years, numerous studies have demonstrated that the uptake of ${ }^{18} \mathrm{~F}-\mathrm{FDG}$ is related to tumor grade and proliferation status in a wide variety of tumors (36). In general, low-grade, slowly proliferating tumors take up less 18F-FDG than poorly differentiated, rapidly growing tumors (36). Although 18F-FDG is certainly not the tracer of choice to study well differentiated neuroendocrine tumors, it has shown a higher sensitivity in patients with MTC when compared to single photon emission tracers (36-38).

Several studies have now been undertaken using ${ }^{18} \mathrm{~F}$ FDG in patients with elevated calcitonin level indicating recurrent MTC (37-42). It seems that ${ }^{18} \mathrm{~F}$-FDG PET can play a major role in the follow-up of patients with postoperative elevated plasma calcitonin with detection of tumor remnant or recurrence $(7,38)$.

The sensitivity of ${ }^{18} \mathrm{~F}$ - PET for recurrence and residual disease detection per patient is reported to be $44.1 \%-85 \%$, and also provides additional information in a significant fraction of cases (up to 54\%) (37, 39-42). However, ${ }^{18} \mathrm{~F}$ - PET is limited by poorer accuracy in the detection of small lesions, especially in the lung and liver (40). Comparing ${ }^{18} \mathrm{~F}$ - PET with conventional morphologic imaging methods (U/S, CT, MRI) and functional imaging methods with single-photon emitters in several studies, it can be noted that the ${ }^{18} \mathrm{~F}$ - PET revealed metastatic lesions in a higher percentage of patients $(37,38,43)$. Other studies have suggested that ${ }^{18} \mathrm{~F}$ - PET imaging is more sensitive in patients with rapidly progressive disease than those with slowly rising calcitonin levels (39).

In a study, the authors compared ${ }^{99} \mathrm{mTc}(\mathrm{V})$-DMSA scintigraphy, ${ }^{111}$ In-DTPA-octreotide, ultrasound, CT, MRI, and ${ }^{18} \mathrm{~F}$ FDG PET and concluded that ${ }^{18}$ F-FDG PET had the highest sensitivity in localizing metastatic disease (43). Another study showed that ${ }^{18}$ F-FDG PET was superior with better sensitivity than CT, MRI, and ${ }^{131}$ I-MIBG in localizing lymph 
node involvement in patients with known MTC and postoperatively elevated calcitonin levels (7). The location of disease recurrence greatly influences the selection of the appropriate imaging modality. ${ }^{18} \mathrm{~F}$-FDG PET, in comparison with CT and MRI, demonstrates higher sensitivity for lesions in neck, supraclavicular, and mediastinal lymph nodes (7). However, CT shows higher efficacy for detection of liver and lung metastases; whereas, ${ }^{18}$ F-FDG PET and MRI were similar (7).

A study performed on the prognostic value of ${ }^{18} \mathrm{~F}-\mathrm{FDG}$ PET, showed that 55\% of PET-positive patients succumbed to their disease; whereas, 93\% of PET-negative patients remained disease free, with a follow-up period of about 44 months (44). Several researchers have correlated the detection rate of MTC recurrence with calcitonin levels and its doubling times (45). It is suggested that ${ }^{18} \mathrm{~F}$-FDG PET imaging is more sensitive in patients with rapidly progressive disease than those with slowly rising calcitonin levels (45). Data from studies indicate that ${ }^{18} \mathrm{~F}-\mathrm{FDG}$ PET or ${ }^{18} \mathrm{~F}-\mathrm{FDG}{ }_{\mathrm{p}} \mathrm{ET} / \mathrm{CT}$ has its greatest utility in patients with calcitonin levels greater than $1000 \mathrm{pg} / \mathrm{ml}(37,41,42,45)$. Using an arbitrary cut-off of $1000 \mathrm{pg} / \mathrm{ml}$, the sensitivity for lesion detection in suspected residual, recurrent, or metastatic MTC increased, in three different studies from $62 \%$ to $78 \%$, from $47.4 \%$ to $80 \%$, and from $44.1 \%$ to $86.7 \%$, respectively $(14,41,42)$. These data also suggest that ${ }^{18} \mathrm{~F}$-FDG PET and ${ }^{18} \mathrm{~F}$-FDG PET/CT have limited usage in patients with low calcitonin levels $(<1000 \mathrm{pg} / \mathrm{mL})$, as the overall sensitivity was only $20 \%-36.8 \%(37,41,42,45)$. It seems that the relatively low sensitivity in lesion detection in cases with low calcitonin levels is likely a reflection of microscopic disease or a smaller tumor burden. In general, it is known that limitations of ${ }^{18} \mathrm{~F}-\mathrm{FDG}$ PET imaging in neuroendocrine tumors are the small size and the slow growth rate of the lesions (29). Studies have also shown that among the patients with MEN IIA syndrome the sensitivity of ${ }^{18}$ F-FDG PET/CT for MTC recurrence was significant lower $(0-23 \%)$ and for patients with calcitonin levels < 2000pg/ $\mathrm{mL}$ this fell to zero $(0 \%)(41,42)$. These findings are in accordance with the results of other studies which support that MEN IIA disease induces more indolent MTCs, and as ${ }^{18} \mathrm{~F}-\mathrm{FDG}$ uptake relies on the biological aggressiveness of the tumor, the detection sensitivity of the method is low $(41,42,46)$.

\subsubsection{Other Positron-Emitting Radiopharmaceuticals for PET Imaging}

Given the heterogeneity of MTC phenotypic expression and the results of the studies analyzed above, it seems that $\left[{ }^{18} \mathrm{~F}\right]$ FDG may not be the ideal radiotracer for imaging MTC. It is probably a suitable PET radiopharmaceutical to detect a small subset of biologically aggressive tumors that overexpress glucose transporter proteins. Other novel non- ${ }^{18} \mathrm{~F}-\mathrm{FDG}$ positron-emitting radiopharma- ceuticals such as: a) ${ }^{18} \mathrm{~F}$-fluorodihydroxyphenylalanine $\left({ }^{18} \mathrm{~F}-\mathrm{DOPA}\right)$ and b) ${ }^{68} \mathrm{Ga}$-labelled somatostatin analogues.

\section{3. ${ }^{18}$ F-DOPA}

${ }^{18} \mathrm{~F}-\mathrm{DOPA}$ is the precursor to the neurotransmitters dopamine, norepinephrine and epinephrine, collectively known as catecholamines. PET with 18 F-DOPA, provides a functional approach of pathologies, organs or tissues where enhanced intracellular transport and decarboxylation of the amino acid dihydroxyphenylalanine is the diagnostic target, allowing the visualization of the sympathetic cells $(47,48)$.

In most of the comparative studies the sensitivity of ${ }^{18} \mathrm{~F}$ DOPA PET is higher than ${ }^{18} \mathrm{~F}-\mathrm{FDG}$ PET in detection of MTC recurrence $(47,48)$. In 2001, investigators have reported that the sensitivity of ${ }^{18}$ F-DOPA PET was $63 \%$ for MTC detection, while more recent studies have shown higher rates of sensitivity between $74 \%$ and $87 \%$ (47-50). Some authors recommend ${ }^{18} \mathrm{~F}$-DOPA PET as a one-stop diagnostic procedure to provide both functional and morphological data to select those patients who may benefit from reoperation with curative intent $(50,51)$. The difference in ${ }^{18} \mathrm{~F}-\mathrm{DO}$ PA uptake seems to be related to MTC differentiation and proliferation (52).

Other data have supported that the combination of ${ }^{18} \mathrm{~F}$ DOPA and ${ }^{18} \mathrm{~F}-\mathrm{FDG}$ PET may give the highest sensitivity and specificity (50). The veritable cut-off value of calcitonin levels that could be predictive of a positive ${ }^{18} \mathrm{~F}-\mathrm{DOPA}$ PET scan still remains controversial. Some authors have suggested a value $>500 \mathrm{ng} / \mathrm{l}$, although others suggested a lower value $>150 \mathrm{pg} / \mathrm{ml}(49,51)$. Some investigators suggested the use of ${ }^{18} \mathrm{~F}$-DOPA PET/CT as the first-choice examination in biochemically recurrent MTC because it seems that may offer increased sensitivity for identifying recurrence, assessing prognosis and guiding selection on appropriate treatment (52).

The radiolabelled metabolite ${ }^{18} \mathrm{~F}$-fluorodopamine $\left({ }^{18} \mathrm{~F}\right.$ DA) may be an alternative radiopharmaceutical to ${ }^{18} \mathrm{~F}$ DOPA PET, as it has been shown to localize an MTC metastasis in a patient with MEN IIA(53). ${ }^{18} \mathrm{~F}-\mathrm{DA}$ has been shown to be sensitive for the evaluation of NETs of chromaffin origin, pheochromocytomas and paragangliomas but larger series are required for MTC detection $(54,55)$

\section{4. ${ }^{68}$ Ga-labelled Somatostatin Analogues}

Somatostatin analogues labelled with positron-emitting radionuclides are used for imaging with PET cameras or hybrid PET/CT cameras with great potential due to two advantages they have over $\gamma$-emitting analogues (8). The most used radioisotope is ${ }^{68}$ Gallium, which is available from an in-house generator, rendering its production independent of an onsite cyclotron (6). ${ }^{68} \mathrm{Ga}$ labelled somatostatin analogues ( ${ }^{68} \mathrm{Ga}$-DOTA-TOC or ${ }^{68} \mathrm{Ga}$-DOTANOC) represent also a promising tool for evaluation of the expression of somatostatin receptors in patients with 
metastatic neuroendocrine tumors in which therapy with ${ }^{177} \mathrm{Lu}$ - or ${ }^{90}$ Y-labelled DOTA-TATE is planned $(56,57)$.

A study has shown that ${ }^{68} \mathrm{Ga}$-DOTATATE PET/CT had a sensitivity of $72 \%$ in detection of MTC recurrence in patients with elevated calcitonin levels postoperatively, and this rate was similar to ${ }^{18} \mathrm{~F}$-FDG PET/CT sensitivity of $78 \%$ (58). The researchers concluded that ${ }^{68} \mathrm{Ga}$-DOTATATE PET/ CT could be a useful complementary imaging method which could identify patients suitable for targeted radionuclide somatostatin analogue therapy (58). A very recent study compared ${ }^{18} \mathrm{~F}$-FDG, ${ }^{18} \mathrm{~F}$-DOPA and ${ }^{68} \mathrm{Ga}$-somatostatin analogues PET/CT imaging in patients with residual/recurrent MTC suspected on the basis of elevated serum calcitonin levels and showed that ${ }^{18} \mathrm{~F}$-DOPA PET/ CT was the most useful imaging method for detecting recurrent MTC lesions performing better than ${ }^{18} \mathrm{~F}-\mathrm{FDG}$ and ${ }^{68} \mathrm{Ga}$-somatostatin analogue PET/CT (59). In another retrospective study that detected the extent of disease in MTC using ${ }^{68} \mathrm{Ga}$-DOTATATE and ${ }^{18} \mathrm{~F}$-FDG PET/CT there was nonsignificant difference in per-patient sensitivities, $72.2 \%$ and $77.8 \%$, respectively (58).

\section{Conclusions}

There is no single sensitive diagnostic imaging method to reveal all MTC recurrences. Conventional morphologic imaging methods (US, CT, MRI) frequently fail to reveal the recurrent lesions. Some new radiopharmaceuticals are under investigation and others can be considered either of historical or experimental value and the use of others, like ${ }^{99 \mathrm{~m}} \mathrm{Tc}(\mathrm{V})$-DMSA, is going to be abandoned. The sensitivity of ${ }^{123_{1}} /{ }^{131}{ }_{1}$-MIBG and Octreoscan, the most used radiopharmaceuticals in neuroendocrine tumors, is low and has been reported to be between 30\% and $71 \%$. It seems that ${ }^{18} \mathrm{~F}-\mathrm{FDG}$ PET or PET/CT can play a major role in the follow-up of patients with postoperative elevated plasma calcitonin and the sensitivity for recurrence and residual disease detection per patient is reported to be 44.1-85\%. ${ }^{18} \mathrm{~F}-\mathrm{FDG}$ PET also provides additional information in a significant fraction of cases (up to 54\%). Preliminary data suggest that the use of other PET tracers, such as ${ }^{18} \mathrm{~F}$-DOPA and ${ }^{68} \mathrm{Ga}$-DOTATOC or ${ }^{68} \mathrm{Ga}$-DOTATATE, may provide a better lesion detection rate than does ${ }^{18} \mathrm{~F}-\mathrm{FDG}$.

\section{Acknowledgements}

There is no Acknowledgements.

\section{Authors' Contribution}

None declared.

\section{Funding/Support}

There is no Funding/Support.

\section{Financial Disclosure}

There is no Financial Disclosure.

\section{References}

1. Kloos RT, Eng C, Evans DB, Francis GL, Gagel RF, Gharib H, et al. Medullary thyroid cancer: management guidelines of the American Thyroid Association. Thyroid. 2009;19(6):565-612.

2. Leboulleux S, Baudin E, Travagli JP, Schlumberger M. Medullary thyroid carcinoma. Clin Endocrinol (Oxf). 2004;61(3):299-310.

3. Schlumberger M, Carlomagno F, Baudin E, Bidart JM, Santoro M. New therapeutic approaches to treat medullary thyroid carcinoma. Nat Clin Pract Endocrinol Metab. 2008;4(1):22-32.

4. Franc S, Niccoli-Sire P, Cohen R, Bardet S, Maes B, Murat A, et al. Complete surgical lymph node resection does not prevent authentic recurrences of medullary thyroid carcinoma. Clin Endocrinol (Oxf). 2001;55(3):403-409.

5. Modigliani Elisabeth, Cohen Regis, Campos Jose-Marie, ConteDevolx Bernard, Maes Beatrice, Boneu Andree, et al. Prognostic factors for survival and for biochemical cure in medullary thyroid carcinoma: results in 899 patients. Clin Endocrinol (Oxf). 1998;48(3):265-273.

6. Rufini Vittoria, Castaldi Paola, Treglia Giorgio, Perotti Germano, Gross Milton D, Al-Nahhas Adil, et al. Nuclear medicine procedures in the diagnosis and therapy of medullary thyroid carcinoma. Biomedicine \& Pharma cotherapy. 2008;62(3):139-146.

7. Szakall S, Jr, Esik O, Bajzik G, Repa I, Dabasi G, Sinkovics I, et al 18F-FDG PET detection of lymph node metastases in medullary thyroid carcinoma. J Nucl Med. 2002;43(1):66-71.

8. Skoura Evangelia, Papachristou Maria, Datseris Ioannis E. The Role of Nuclear Medicine in Imaging and Therapy of Neuroendocrine Tumors. Hospital Chronicles. 2012;7(2):81-90.

9. Bombardieri E, Seregni E, Villano C, Chiti A, Bajetta E. Position of nuclear medicine techniques in the diagnostic work-up of neuroendocrine tumors. QJ Nucl Med Mol Imaging. 2004;48(2):150-63.

10. Clarke S, ${ }_{\mathrm{E}}$ ll P J, Gambhir SS . Medullary thyroid cancer. 3 ed. Clarke S, ${ }_{\mathrm{E}}$ Il P J, Gambhir SS, editors: Churcill Livingstone; 2004.

11. Verga U, Muratori F, Di Sacco G, Banfi F, Libroia A. The role of radiopharmaceuticals MIBG and (V) DMSA in the diagnosis of medullary thyroid carcinoma. Henry Ford Hosp Med J. 1989;37(34):175-7.

12. Clarke S, Lazarus C, Maisey M. Experience in imaging medullary thyroid carcinoma using $99 \mathrm{mTc}(\mathrm{V})$ dimercaptosuccinic acid (DMSA). Henry Ford Hosp Med J. 1989;37(3-4):167-8.

13. Bombardieri E, Coliva A, Maccauro M, Seregni E, Orunesu E, Chiti A, et al. Imaging of neuroendocrine tumours with gamma-emitting radiopharmaceuticals. Q J Nucl Med Mol Imaging. 2010;54(1):3-15.

14. Sandrock D, Blossey HC, Steinroeder M, Munz DL. Contribution of different scintigraphic techniques to the management of medullary thyroid carcinoma. Henry Ford Hosp Med J. 1989;37(34):173-4

15. Baulieu Jean-Louis, Guilloteau Denis, Delisle Marie-Joelle, Perdrisot Remy, Gardet Paule, Delépine Nicole, et al. Radioiodinated meta-iodobenzylguanidine uptake in medullary thyroid cancer: A French cooperative study. Cancer. 1987;60(9):2189-2194.

16. Kwekkeboom DJ, Reubi J, Krenning EP, Ell PJ Gambhir SS. Peptide receptor scintigraphy in oncology. Kwekkeboom DJ, Reubi J, Krenning EP, Ell PJ Gambhir SS, editors: London; 2004.

17. Hicks RJ. Use of molecular targeted agents for the diagnosis staging and therapy of neuroendocrine malignancy. Cancer Imaging. 2010;10 Spec no A:S83-91.

18. Arslan N, Ilgan S, Yuksel D, Serdengecti M, Bulakbasi N, Ugur O et al. Comparison of In-111 octreotide and Tc-99m (V) DMSA scintigraphy in the detection of medullary thyroid tumor foci in patients with elevated levels of tumor markers after surgery. Clin Nucl Med. 2001;26(8):683-8.

19. Baudin E, Schlumberger M, Lumbroso J, Travagli JP, Caillou B, Parmentier C. Octreotide scintigraphy in patients with differentiated thyroid carcinoma: contribution for patients with negative radioiodine scan.J Clin Endocrinol Metab. 1996;81(7):2541-4.

20. Kaltsas G, Korbonits M, Heintz E, Mukherjee JJ, Jenkins PJ, Chew SL, et al. Comparison of somatostatin analog and meta-iodobenzylguanidine radionuclides in the diagnosis and localization of advanced neuroendocrine tumors. J Clin Endocrinol Metab. 2001;86(2):895-902. 
21. Reubi JC, Chayvialle JA, Franc B, Cohen R, Calmettes C, Modigliani E. Somatostatin receptors and somatostatin content in medullary thyroid carcinomas. Lab Invest. 1991;64(4):567-73.

22. Behr TM, Becker W. Metabolic and receptor imaging of metastatic medullary thyroid cancer: does anti-CEA and somatostatin-receptor scintigraphy allow for prognostic predictions? EurJ Nucl Med.1999;26(1):70-1.

23. Plachcinska A, Mikolajczak R, Maecke H, Mlodkowska E, KunertRadek J, Michalski A, et al. Clinical usefulness of 99mTc-EDDA/ HYNIC-TOC scintigraphy in oncological diagnostics: a pilot study. Cancer Biother Radiopharm. 2004;19(2):261-70.

24. Czepczynski R, Parisella MG, Kosowicz J, Mikolajczak R, Ziemnicka K, Gryczynska M, et al. Somatostatin receptor scintigraphy using 99mTc-EDDA/HYNIC-TOC in patients with medullary thyroid carcinoma. Eur J Nucl Med Mol Imaging. 2007;34(10):1635-45.

25. Arnstein NB, Juni JE, Sisson JC, Lloyd RV, Thompson NW. Recurrent medullary carcinoma of the thyroid demonstrated by thallium-201 scintigraphy. J Nucl Med.1986;27(10):1564-8.

26. Hoefnagel CA, Delprat CC, Marcuse HR, de Vijlder JJ. Role of thallium-201 total-body scintigraphy in follow-up of thyroid carcinoma. J Nucl Med.1986;27(12):1854-7.

27. Learoyd DL, Roach PJ, Briggs GM, Delbridge LW, Wilmshurst EG, Robinson BG. Technetium-99m-sestamibi scanning in recurrent medullary thyroid carcinoma. J Nucl Med.1997;38(2):227-30.

28. Ugur Omer, Kostakoglu Lale, Hui Edmond T, Fisher Darrell R, Garmestani Kayhan, Gansow Otto A, et al. Comparison of the targeting characteristics of various radioimmunoconjugates for radioimmunotherapy of neuroblastoma: Dosimetry calculations incorporating cross-organ beta doses. Nucl Med Biol. 1996;23(1):1-8

29. Behr Thomas M, Gratz Stefan, Markus Peter M, Dunn Robert M, Hüfner Michael, Schauer Alfred, et al. Anti-carcinoembryonic antigen antibodies versus somatostatin analogs in the detection of metastatic medullary thyroid carcinoma. Cancer. 1997;80(S12):2436-2457.

30. Busnardo B, Girelli ME, Simioni N, Nacamulli D, Busetto E. Nonparallel patterns of calcitonin and carcinoembryonic antigen levels in the follow-up of medullary thyroid carcinoma. Cancer. 1984;53(2):278-85.

31. Laverman P, Sosabowski JK, Boerman OC, Oyen WJ. Radiolabelled peptides for oncological diagnosis. Eur J Nucl Med Mol Imaging. 2012;39 Suppl 1:S78-92.

32. Reubi JC, Waser B. Unexpected high incidence of cholecystokinin-B/gastrin receptors in human medullary thyroid carcinomas. Int J Cancer. 1996;67(5):644-7.

33. Behr TM, Jenner N, Behe M, Angerstein C, Gratz S, Raue F, et al. Radiolabeled peptides for targeting cholecystokinin-B/gastrin receptor-expressing tumors. J Nucl Med.1999;40(6):1029-44.

34. Froberg AC, de Jong M, Nock BA, Breeman WA, Erion JL, Maina T, et al. Comparison of three radiolabelled peptide analogues for CCK-2 receptor scintigraphy in medullary thyroid carcinoma. EurJ Nucl Med Mol Imaging. 2009;36(8):1265-72.

35. Gotthardt M, Behe MP, Beuter D, Battmann A, Bauhofer A, Schurrat $\mathrm{T}$, et al. Improved tumour detection by gastrin receptor scintigraphy in patients with metastasised medullary thyroid carcinoma. Eur J Nucl Med Mol Imaging. 2006;33(11):1273-9.

36. Ambrosini V, Tomassetti P, Franchi R, Fanti S. Imaging of NETs with PET radiopharmaceuticals. Q J Nucl Med Mol Imaging. 2010;54(1):16-23.

37. de Groot JW, Links TP, Jager PL, Kahraman T, Plukker JT. Impact of 18F-fluoro-2-deoxy-D-glucose positron emission tomography (FDG-PET) in patients with biochemical evidence of recurrent or residual medullary thyroid cancer. Ann Surg Oncol. 2004;11(8):786-94.

38. Khan N, Oriuchi N, Higuchi T, Endo K. Review of fluorine-18-2-fluoro-2-deoxy-D-glucose positron emission tomography (FDG-PET) in the follow-up of medullary and anaplastic thyroid carcinomas. Cancer Control. 2005;12(4):254-60.

39. Brandt-Mainz K, Muller SP, Gorges R, Saller B, Bockisch A. The value of fluorine-18 fluorodeoxyglucose PET in patients with medullary thyroid cancer. Eur J Nucl Med. 2000;27(5):490-6.

40. Iagaru A, Masamed R, Singer PA, Conti PS. Detection of occult medullary thyroid cancer recurrence with 2-deoxy-2-[F-18]fluoroD-glucose-PET and PET/CT. Mol Imaging Biol. 2007;9(2):72-7.

41. Skoura E, Datseris IE, Rondogianni P, Tsagarakis S, Tzanela M, Skilakaki M, et al. Correlation between Calcitonin Levels and [(18)F]FDG-PET/CT in the Detection of Recurrence in Patients with Sporadic and Hereditary Medullary Thyroid Cancer. ISRN Endocrinol. 2012;2012:375231.

42. Skoura E, Rondogianni P, Alevizaki M, Tzanela M, Tsagarakis S, Piaditis G, et al. Role of [(18)F]FDG-PET/CT in the detection of occult recurrent medullary thyroid cancer. Nucl Med Commun. 2010;31(6):567-75.

43. Rubello D, Rampin L, Nanni C, Banti E, Ferdeghini M, Fanti S, et al. The role of 18F-FDG PET/CT in detecting metastatic deposits of recurrent medullary thyroid carcinoma: a prospective study. Eur J Surg Oncol. 2008;34(5):581-6.

44. Bogsrud TV, Karantanis D, Nathan MA, Mullan BP, Wiseman GA, Kasperbauer JL, et al. The prognostic value of 2-deoxy-2-[18F]fluoro-D-glucose positron emission tomography in patients with suspected residual or recurrent medullary thyroid carcinoma. Mol Imaging Biol. 2010;12(5):547-53.

45. Ong SC, Schoder H, Patel SG, Tabangay-Lim IM, Doddamane I, Gonen M, et al. Diagnostic accuracy of 18F-FDG PET in restaging patients with medullary thyroid carcinoma and elevated calcitonin levels. J Nucl Med. 2007;48(4):501-7.

46. Pestourie C, Theze B, Kuhnast B, Le Helleix S, Gombert K, Dolle $\mathrm{F}$, et al. PET imaging of medullary thyroid carcinoma in MEN2A transgenic mice using 6-[(18)F]F-L-DOPA. Eur J Nucl Med Mol Imaging. 2010;37(1):58-66.

47. Beuthien-Baumann B, Strumpf A, Zessin J, Bredow J, Kotzerke J. Diagnostic impact of PET with 18F-FDG, 18F-DOPA and 3-O-methyl6-[18F]fluoro-DOPA in recurrent or metastatic medullary thyroid carcinoma. Eur J Nucl Med Mol Imaging. 2007;34(10):1604-9.

48. Hoegerle S, Altehoefer C, Ghanem N, Brink I, Moser E, Nitzsche E. 18F-DOPA positron emission tomography for tumour detection in patients with medullary thyroid carcinoma and elevated calcitonin levels. Eur J Nucl Med. 2001;28(1):64-71.

49. Koopmans KP, de Groot JW, Plukker JT, de Vries EG, Kema IP, Sluiter WJ, et al. 18F-dihydroxyphenylalanine PET in patients with biochemical evidence of medullary thyroid cancer: relation to tumor differentiation.J Nucl Med. 2008;49(4):524-31.

50. Marzola MC, Pelizzo MR, Ferdeghini M, Toniato A, Massaro A, Ambrosini V, et al. Dual PET/CT with (18)F-DOPA and (18)F-FDG in metastatic medullary thyroid carcinoma and rapidly increasing calcitonin levels: Comparison with conventional imaging. Eur J Surg Oncol. 2010;36(4):414-21.

51. Luster M, Karges W, Zeich K, Pauls S, Verburg FA, Dralle H, et al. Clinical value of 18-fluorine-fluorodihydroxyphenylalanine positron emission tomography/computed tomography in the follow-up of medullary thyroid carcinoma. Thyroid. 2010;20(5):52733.

52. Wong KK, Laird AM, Moubayed A, Chondrogiannis S, Marzola MC, Evangelista L, et al. How has the management of medullary thyroid carcinoma changed with the advent of $18 \mathrm{~F}-\mathrm{FDG}$ and non-18F-FDG PET radiopharmaceuticals. Nucl Med Commun. 2012;33(7):679-88

53. Gourgiotis L, Sarlis NJ, Reynolds JC, VanWaes C, Merino MJ, Pacak K. Localization of medullary thyroid carcinoma metastasis in a multiple endocrine neoplasia type $2 \mathrm{~A}$ patient by 6-[18F]-fluorodopamine positron emission tomography. J Clin Endocrinol Metab. 2003;88(2):637-41.

54. Ilias I, Pacak K. A clinical overview of pheochromocytomas/paragangliomas and carcinoid tumors. Nucl Med Biol. 2008;35 Suppl 1:S27-34.

55. Koopmans KP, Neels ON, Kema IP, Elsinga PH, Links TP, de Vries EG, et al. Molecular imaging in neuroendocrine tumors: molecular uptake mechanisms and clinical results. Crit Rev Oncol Hematol. 2009;71(3):199-213.

56. Ambrosini V, Castellucci P, Rubello D, Nanni C, Musto A, Allegri V, et al. 68Ga-DOTA-NOC: a new PET tracer for evaluating patients with bronchial carcinoid. Nucl Med Commun. 2009;30(4):281-6.

57. Antunes P, Ginj M, Zhang H, Waser B, Baum RP, Reubi JC, et al. Are radiogallium-labelled DOTA-conjugated somatostatin ana- 
logues superior to those labelled with other radiometals? Eur $J$ Nucl Med Mol Imaging. 2007;34(7):982-93.

58. Conry BG, Papathanasiou ND, Prakash V, Kayani I, Caplin M, Mahmood S, et al. Comparison of (68)Ga-DOTATATE and (18)F-fluorodeoxyglucose PET/CT in the detection of recurrent medullary thyroid carcinoma. Eur J Nucl Med Mol Imaging. 2010;37(1):49-57. 59. Treglia G, Castaldi P, Villani MF, Perotti G, de Waure C, Filice A et al. Comparison of 18F-DOPA, 18F-FDG and 68Ga-somatostatin analogue PET/CT in patients with recurrent medullary thyroid carcinoma. Eur J Nucl Med Mol Imaging. 2012;39(4):569-80. 